\title{
BREAKDOWN DEGRADATION ASSOCIATED WITH ELEMENTARY SCREW DISLOCATIONS IN 4H-SiC $P^{+} N$ JUNCTION RECTIFIERS
}

P. G. NEUDECK*, W. HUANG**, AND M. DUDLEY**

*NASA Lewis Research Center, M.S. 77-1, 21000 Brookpark Rd., Cleveland, OH 44135

**Dept. of Materials Science \& Engineering, SUNY, Stony Brook, NY 11794

\section{ABSTRACT}

It is well-known that $\mathrm{SiC}$ wafer quality deficiencies are delaying the realization of outstandingly superior $4 \mathrm{H}-\mathrm{SiC}$ power electronics. While efforts to date have centered on eradicating micropipes (i.e., hollow core super-screw dislocations with Burgers vector $>2 \mathrm{c}$ ), 4H-SiC wafers and epilayers also contain elementary screw dislocations (i.e., Burgers vector $=1 \mathrm{c}$ with no hollow core) in densities on the order of thousands per $\mathrm{cm}^{2}$, nearly 100 -fold micropipe densities. This paper describes an initial study into the impact of elementary screw dislocations on the reverse-bias current-voltage (I-V) characteristics of $4 \mathrm{H}-\mathrm{SiC} \mathrm{p}^{+} n$ diodes. First, Synchrotron White Beam X-ray Topography (SWBXT) was employed to map the exact locations of elementary screw dislocations within small-area $4 \mathrm{H}-\mathrm{SiC} \mathrm{p}^{+} \mathrm{n}$ mesa diodes. Then the high-field reverse leakage and breakdown properties of these diodes were subsequently characterized on a probing station outfitted with a dark box and video camera. Most devices without screw dislocations exhibited excellent characteristics, with no detectable leakage current prior to breakdown, a sharp breakdown I-V knee, and no visible concentration of breakdown current. In contrast devices that contained at least one elementary screw dislocation exhibited a 5\% to $35 \%$ reduction in breakdown voltage, a softer breakdown I-V knee, and visible microplasmas in which highly localized breakdown current was concentrated. The locations of observed breakdown microplasmas corresponded exactly to the locations of elementary screw dislocations identified by SWBXT mapping. While not as detrimental to $\mathrm{SiC}$ device performance as micropipes, the undesirable breakdown characteristics of elementary screw dislocations could nevertheless adversely affect the performance and reliability of $4 \mathrm{H}-\mathrm{SiC}$ power devices.

\section{INTRODUCTION}

The inherent physical properties of silicon carbide ( $\mathrm{SiC}$ ) are extremely well-suited for power semiconductor electronic devices. These include a higher breakdown field (> 5 times that of $\mathrm{Si}$ ) that permits much smaller drift regions (i.e., much lower drift region resistances), a higher thermal conductivity ( $>3$ times that of $\mathrm{Si}$ ) that permits better heat dissipation, and a wide bandgap energy (2.9 eV for $6 \mathrm{H}-\mathrm{SiC}, 3.2 \mathrm{eV}$ for $4 \mathrm{H}-\mathrm{SiC}$ ) that enables higher junction operating temperatures [1]. Theoretical appraisals have suggested that SiC power MOSFET's and diode rectifiers would operate over higher voltage and temperature ranges, have superior switching characteristics, and yet have die sizes nearly 20 times smaller than correspondingly rated silicon-based devices [2]. This would enable large power system performance improvements, which has fueled speculation that $\mathrm{SiC}$ may someday supplant silicon in many high-power electronic applications [3]. Before this can occur however, $\mathrm{SiC}$ power semiconductor components must demonstrate capabilities that are commonplace to well-developed silicon power components in use today. As a minimum, highpower solid-state devices must: 1) block high voltages in the off-state with negligible leakage current, 2) carry high on-state currents with minimal parasitic voltage drop, 3) rapidly switch backand-forth between on-state and off-state, 4) function reliably without a single failure over the operational lifetime of the system, and 5) be cost-effective to produce and incorporate into high power systems. While some prototype $\mathrm{SiC}$ power devices produced to date meet one or two of these 5 criteria, $\mathrm{SiC}$ devices that meet even a majority of these criteria do not as yet exist.

Almost all SiC power electronics are being developed on commercially available c-axis $6 \mathrm{H}$ - and $4 \mathrm{H}-\mathrm{SiC}$ wafers whose surfaces lie roughly perpendicular (to within $10^{\circ}$ ) of the crystallographic caxis. Efforts to make mass-producible wafers and devices oriented in other SiC polytypes and other crystallographic directions have to date proven much less-acceptable for high-field device performance than c-axis oriented $4 \mathrm{H}$ - and $6 \mathrm{H}-\mathrm{SiC}$ wafers and epilayers [4]. The $4 \mathrm{H}$ polytype is 
more attractive than the $6 \mathrm{H}$ polytype for power device development, primarily because it has higher carrier mobilities and shallower dopant ionization energies [5].

It is widely recognized that material quality deficiencies are the primary reason why $\mathrm{SiC}$ highpower devices cannot be realized at present. While small-current, small-area high-voltage (1-5 kV) $\mathrm{SiC}$ devices are being prototyped and tested, the high densities of crystallographic defects in $\mathrm{SiC}$ wafers prohibits the attainment of $\mathrm{SiC}$ devices with very high operating currents $(>50 \mathrm{~A})$ that are commonly obtainable in silicon-based high-power electronics [1].

The micropipe is well-documented as the most harmful defect to $4 \mathrm{H}-$ and $6 \mathrm{H}-\mathrm{SiC}$ power device performance [6]. As discussed in References [7-10], micropipes are hollow-core screw dislocations with Burgers vectors $\geq 2 \mathrm{c}$ formed during the $\mathrm{SiC}$ sublimation wafer growth process. These tubular void defects run perpendicular to the polished wafer surface roughly parallel to the crystallographic c-axis, deforming the nearby $\mathrm{SiC}$ lattice and spinning off substrate basal plane dislocation loops. Because of the non-terminating behavior of screw dislocations, both hollowcore and non-hollow-core screw dislocations and associated crystal lattice stresses are replicated in subsequently grown $\mathrm{SiC}$ epilayers $[11,12]$. Micropipe defects cause premature breakdown pointfailures in SiC high-field devices fabricated in $4 \mathrm{H}-$ and $6 \mathrm{H}-\mathrm{SiC}$ c-axis crystals with and without epilayers [6]. To date the high density of micropipe defects has prevented the simultaneous realization of high-voltage SiC devices with sufficient areas to carry high on-state currents. Once micropipes were recognized as the chief material difficulty limiting SiC power device performance, global $\mathrm{SiC}$ research focused on micropipe eradication. This has resulted in commercial micropipe densities falling from hundreds per $\mathrm{cm}^{2}$ to less than 30 per $\mathrm{cm}^{2}$ over the last 4 years $[13,14]$, enabling a corresponding increase in the best reported high voltage $\mathrm{SiC}$ device on-state currents from less than $1 \mathrm{~A}$ in 1993 [15] to around $10 \mathrm{~A}$ in 1997 [16].

While micropipes have been the focus of attention, commercial $4 \mathrm{H}-$ and $6 \mathrm{H}-\mathrm{SiC}$ wafers and epilayers also contain elementary screw dislocations (i.e., Burgers vector $=1 \mathrm{c}$ with no hollow core) in densities on the order of thousands per $\mathrm{cm}^{2}$, nearly 100-fold micropipe densities [7-10]. The electrical impact of these defects on $\mathrm{SiC}$ device performance has largely been overlooked while attention focused on $\mathrm{SiC}$ micropipes, as micropipes are clearly are more harmful to SiC device characteristics than elementary screw dislocations. However as $\mathrm{SiC}$ micropipe densities fall below 1 per $\mathrm{cm}^{2}$ in the best reported wafers [13], the operational effects of elementary screw dislocations must now be considered. This is especially important since all appreciable current (> $1 \mathrm{~A}) \mathrm{SiC}$ power devices are virtually guaranteed to contain these screw dislocations for the foreseeable future. This paper describes an initial study into the impact of elementary screw dislocations on the reverse-bias current-voltage (I-V) characteristics of $4 \mathrm{H}-\mathrm{SiC} \mathrm{p}^{+} \mathrm{n}$ diodes.

\section{EXPERIMENT}

The SiC homoepilayer structure shown in Figure 1 was grown by NASA Lewis on substrates cut from commercially available $\mathrm{n}^{+} 4 \mathrm{H}$ silicon-face $\mathrm{SiC}$ substrates polished $3^{\circ}$ to $4^{\circ}$ off the $(0001)$ $\mathrm{SiC}$ basal plane. $\mathrm{P}^{+} \mathrm{n}$ diodes with $\mathrm{n}$-type dopings varied between $2.5 \times 10^{17}$ to $1.5 \times 10^{18} \mathrm{~cm}^{-3}$ (as measured by $1 \mathrm{MHz} \mathrm{C}-\mathrm{V}$ profiling) were produced by atmospheric pressure chemical vapor deposition using source-gas $\mathrm{Si} / \mathrm{C}$ atomic ratios of 0.16 in the nitrogendoped and 0.09 in the aluminum-doped layers, respectively $[17,18]$. A 2000-3000 A thick aluminum etch mask, which defined circular and square diode mesas ranging in area from $7 \times 10^{-6} \mathrm{~cm}^{2}$ to $4 \times 10^{-4}$ $\mathrm{cm}^{2}$, was applied and patterned by metal liftoff. Diode mesas were defined by etching to a depth of approximately 2-3 $\mu \mathrm{m}$ using reactive ion etching with $90 \% \mathrm{CHF}_{3}: 10 \% \mathrm{O}_{2}$ at $400 \mathrm{~W}$ rf with a chamber pressure of $150 \mathrm{mTorr}$. Capacitance-voltage profiling was carried out using the metal etch mask employed as the topside device contact, while blanket deposited aluminum served as a backside contact.

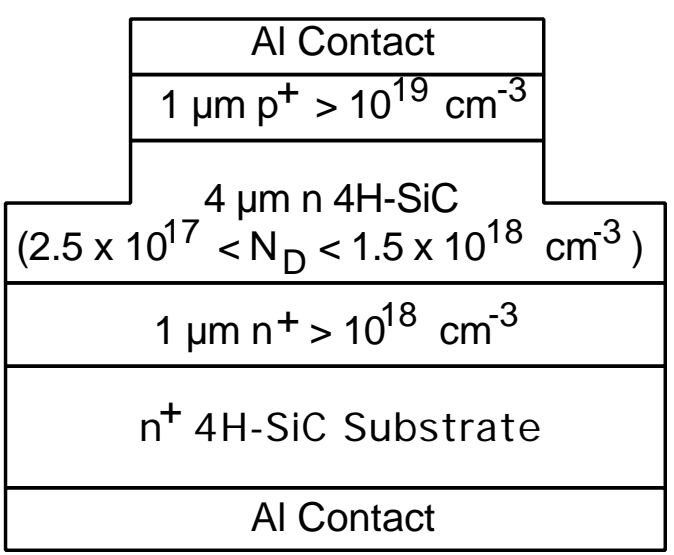

Figure 1: Cross-section of $4 \mathrm{H}-\mathrm{SiC} \mathrm{p}^{+} \mathrm{n}$ junction diodes tested in this work. 
Synchrotron White Beam X-ray Topography (SWBXT) was employed on three occasions to map the exact locations of elementary screw dislocations within small-area $4 \mathrm{H}-\mathrm{SiC} \mathrm{p}^{+} \mathrm{n}$ mesa diodes. Details of this technique and how it is used to detect imperfections in SiC crystal structure can be found in References [7, 8, 19]. The first SWBXT images were recorded with both topside and backside aluminum contacts in place, while a second set of SWBXT images were recorded after aluminum metallization had been stripped from the sample. A third set of images, which was recorded following a lap and polish to remove polycrystalline $\mathrm{SiC}$ that deposited onto the wafer backside during epitaxial growth, yielded the clearest images that most distinctly revealed the locations of crystalline defects. A SWBXT back-reflection image of part of the $4 \mathrm{H}-\mathrm{SiC} \mathrm{p}^{+} \mathrm{n}$ diode wafer is shown in Figure 2. Circular and square diode mesa borders are discernible as somewhat darker regions in this image. As indicated in Figure 2, elementary screw dislocations (Burgers vector $=1 \mathrm{c}$ with no hollow core) image as very small light dots, while screw dislocations with larger Burgers vectors ( $>2 \mathrm{c}$ for micropipes in $4 \mathrm{H}-\mathrm{SiC}$ ) image as larger light rounded areas [10]. This and similar SWBXT images were used to ascertain not only the presence or absence of screw dislocations within each device that was electrically characterized, but also to pinpoint the exact location of the various screw dislocations within each device. Examples of devices with zero, one, two, or more elementary screw dislocations are evident amongst the smaller devices imaged in Figure 2.

The high-field reverse breakdown and leakage properties of these diodes were subsequently characterized on a probing station outfitted with a dark box and video camera. Current-voltage (IV) measurements were taken in total dark and low-light conditions using both a $60 \mathrm{~Hz}$ curve tracer and a computer-controlled I-V source-measure unit. Video data was recorded in low-light conditions that facilitated imaging of diode mesa boundaries in addition to breakdown-bias luminescence, so that the exact positions of nonuniform luminescence within each mesa could be precisely pinpointed and cataloged using a single video frame capture. There were no significant differences between I-V data recorded in total dark and low-light measurement conditions. To

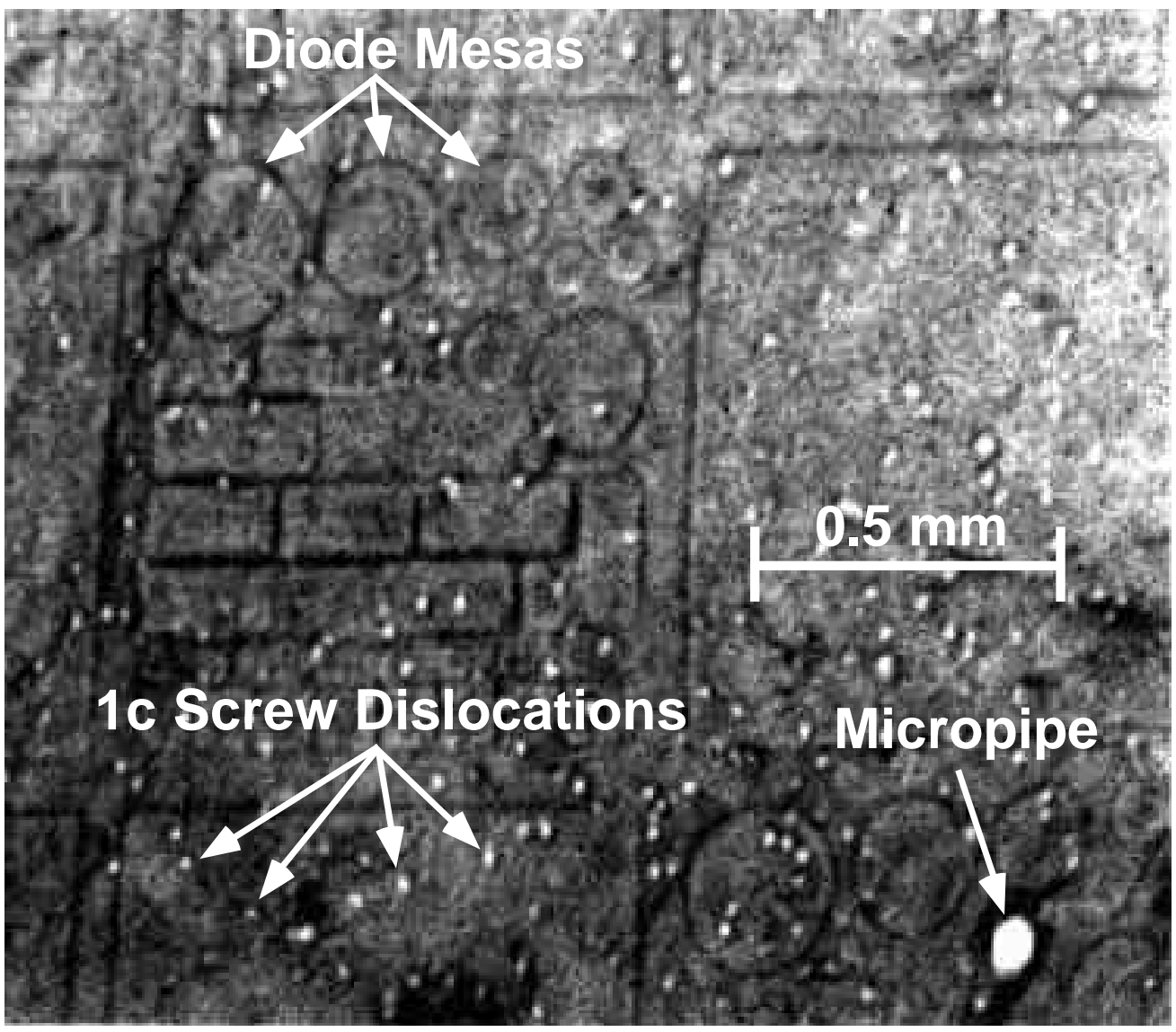

Figure 2: SWBXT back-reflection topograph of part of $4 \mathrm{H}-\mathrm{SiC} \mathrm{p}^{+} \mathrm{n}$ diode wafer showing diode mesas, 1c screw dislocations, and one micropipe. 
permit the clear observation of breakdown-bias luminescence, the sample was measured with no contact metallizations. Sufficient electrical connection to the diodes for these low-current $(<10$ $\mathrm{mA}$ ) measurements was obtained by directly probing the degenerately-doped $\mathrm{p}^{+}$epilayer topside and contacting wafer backside with the probe station chuck. Because reverse breakdown voltages on this $4 \mathrm{H}-\mathrm{SiC}$ diode sample did not exceed $150 \mathrm{~V}$, all measurements were conducted in air without interference from edge-related breakdown phenomena such as surface flashover.

\section{RESULTS}

The results of this study are best introduced by directly comparing representative diodes with and without elementary screw dislocations. Figures 3a, 4a, 5a, and 6a show all data collected on a $240 \mu \mathrm{m} \times 100 \mu \mathrm{m}$ device (hereafter referred to as Diode A), while Figures 3b, 4b, 5b, and 6b show all data recorded on a nearby $260 \mu \mathrm{m}$ x $100 \mu \mathrm{m}$ diode (Diode B). Figure 3 displays enlarged SWBXT back-reflection images of the two devices. The light spot residing inside the Figure $3 \mathrm{~b}$ Diode B mesa indicates the presence of an elementary screw dislocation of Burgers vector 1c with no hollow core [10], whereas there is no such defect present in the Figure 3a rectangular Diode A. The DC reverse-bias I-V characteristics of these devices are shown on a logarithmic current scale in Figure 4 and a linear current scale in Figure 5. Below $60 \mathrm{~V}$ applied reverse bias, the leakage current of both diodes is well below the $1 \times 10^{-5} \mathrm{~mA}$ noise current floor of our measurement apparatus. At around $65 \mathrm{~V}$ reverse bias, Diode B containing the elementary screw dislocation exhibits a very sharp rise in current in Figure $4 \mathrm{~b}$, while the reverse leakage of the screw dislocation-free Diode A remains below the measurement noise floor in Figure 4a. On the linear current scale, the Diode B current increase translates into a softening of the Figure 5b breakdown knee relative to the sharp breakdown knee exhibited by Diode A in Figure 5a. While the soft breakdown of Device B precludes exact quantification of breakdown voltage, Device A clearly exhibits a higher breakdown voltage than Device B. Coinciding with the sharp, several order of magnitude current rise in Figure 5b, a concentrated breakdown microplasma becomes optically observable. This microplasma is seen as the small white spot in the Figure $6 \mathrm{~b}$ low-light optical micrograph of Diode B under $85 \mathrm{~V}$ applied reverse bias. Direct comparison of Figures $3 \mathrm{~b}$ and $6 \mathrm{~b}$ shows that the location of the breakdown microplasma on the Diode B mesa exactly coincides to the location of the elementary screw dislocation revealed by SWBXT. No microplasmas were observed in the screw dislocation-free Diode A (Figure 6a), even when the device is biased well into breakdown at more than $95 \mathrm{~V}$ applied reverse bias. Instead, the screw-dislocation free Device A exhibits a reasonably uniform breakdown luminescence over the entire mesa (too dim to be apparent in low-light conditions of Figure 6a) when a few mA of breakdown current is drawn. When biased beyond $95 \mathrm{~V}$, Diode B exhibits dim bulk breakdown luminescence distributed over the mesa area in addition to the bright localized microplasma. Under these testing conditions where
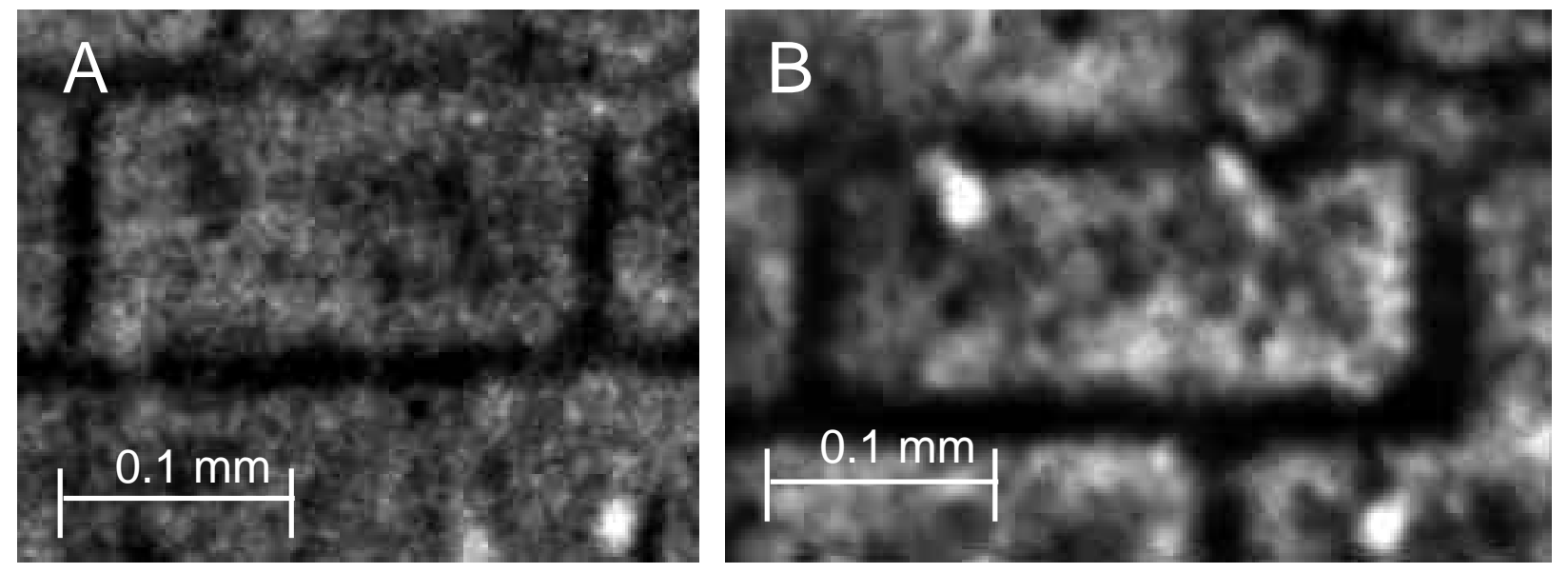

Figure 3: SWBXT back-reflection close-ups of two rectangular $4 \mathrm{H}-\mathrm{SiC} \mathrm{p}^{+} \mathrm{n}$ junction diodes.

a.) Diode $\mathrm{A}$, a $240 \mu \mathrm{m} \times 100 \mu \mathrm{m}$ diode containing no elementary screw dislocations.

b.) Diode B, a $260 \mu \mathrm{m}$ x $100 \mu \mathrm{m}$ diode containing a single elementary screw dislocation. 

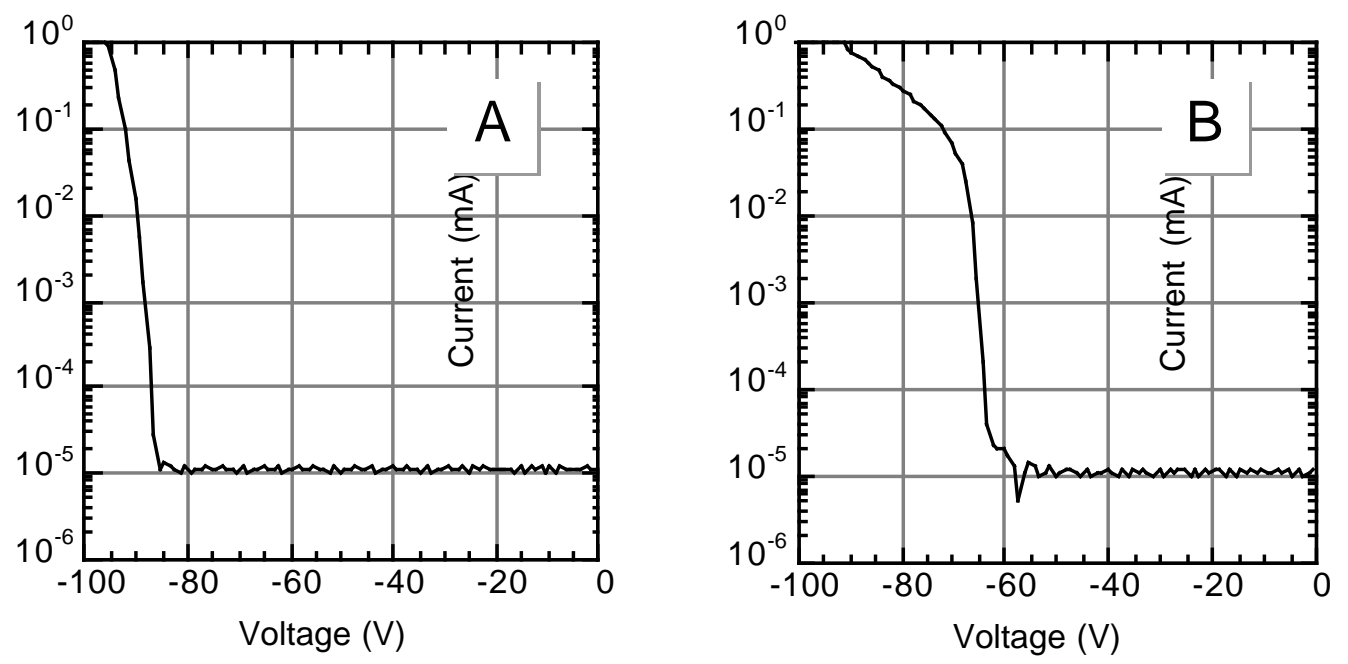

Figure 4: Logarithmic current scale reverse-bias I-V of Diode A and Diode B.
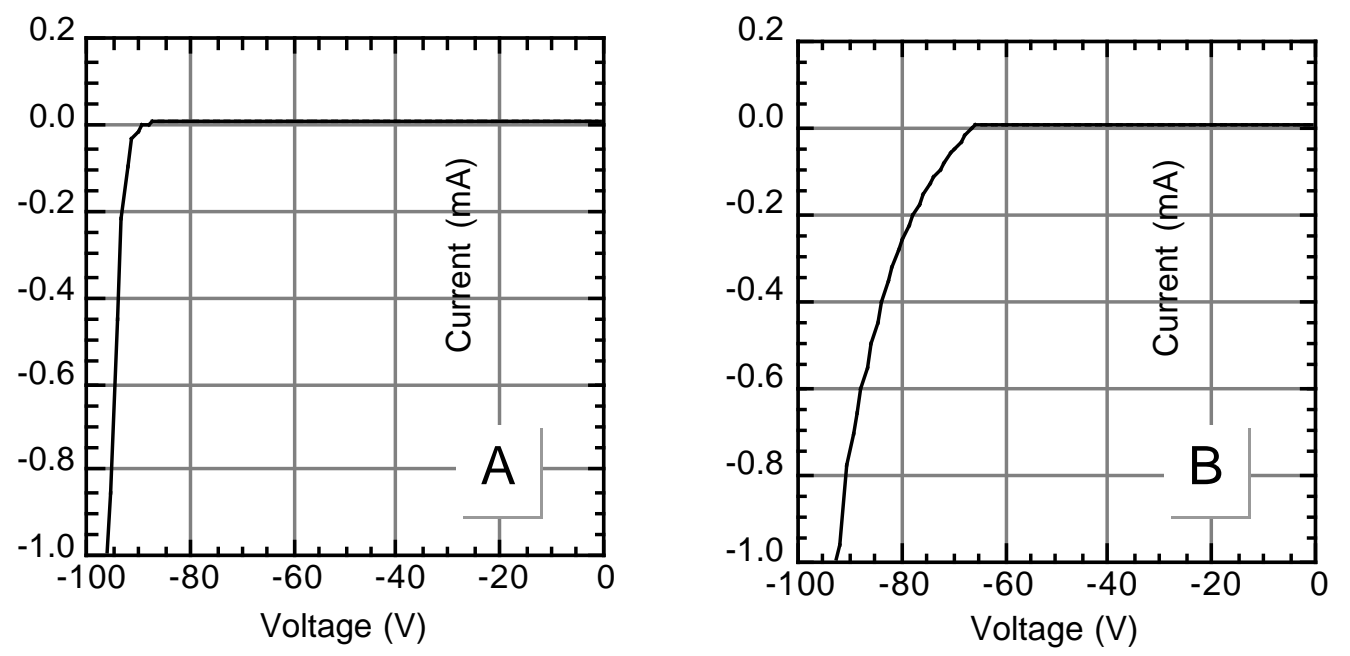

Figure 5: Linear current scale reverse-bias I-V of Diode A and Diode B.
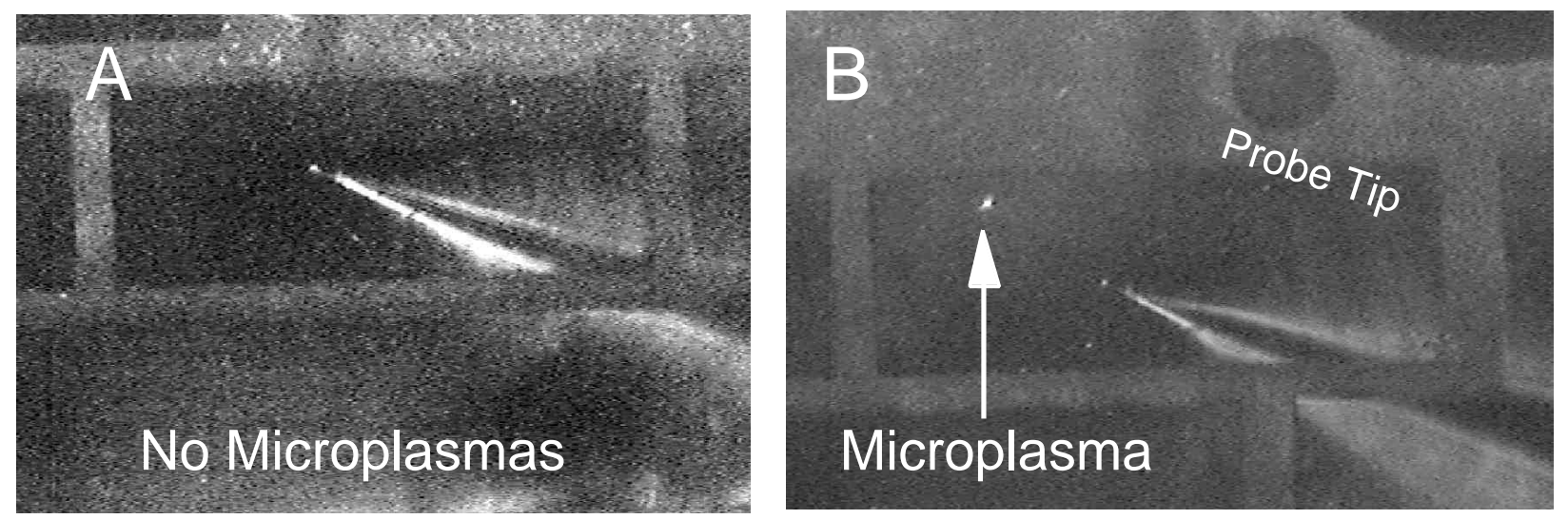

Figure 6: Low-light optical micrographs of Diode A and Diode B breakdown-bias luminescence. 
breakdown current was limited below $10 \mathrm{~mA}$, the microplasmas did not appear to harm the diodes, as no changes in I-V properties were noted despite application of DC breakdown biases over periods as long as several minutes.

Detailed comparisons of the I-V, SWBXT, and breakdown luminescence characteristics of dozens of devices on the same $4 \mathrm{H}-\mathrm{SiC}$ wafer have been carried out to date. Without exception, all devices that SWBXT identified as containing at least one elementary screw dislocation (without screw dislocations larger than 1c Burgers vector) behaved very similarly to Diode B, exhibiting degraded reverse I-V characteristics and breakdown-bias microplasmas located at 1c screw dislocations. Figure 7 compares the semi-logarithmic characteristics of eleven diodes, wherein each diode contained $0,1,2$, or 3 elementary screw dislocations. These diodes range in area from 1.77 $\mathrm{x} 10^{-4} \mathrm{~cm}^{2}$ to $4.91 \times 10^{-4} \mathrm{~cm}^{2}$ and all reside within $1 \mathrm{~mm}$ of each other on the wafer so as to minimize doping variation effects. The diodes containing one or more elementary screw dislocations clearly exhibit very similar behaviors, easily discernible from dislocation-free diodes on a logarithmic current scale. Depending upon one's choice for a definition of reverse breakdown, the breakdown voltage of diodes with elementary screw dislocations lies somewhere between 5\% to $35 \%$ less than the breakdown voltage of screw dislocation-free diodes.

Figure 7 clearly shows that the presence or absence of dislocations is the major factor governing diode reverse I-V characteristics at high applied fields. The number of elementary screw dislocations present in the diode has a less-pronounced impact on reverse I-V properties. Device to device scatter in microplasma turn-on voltages, evident in Figure 7, largely precluded direct quantitative correlation of 1c screw dislocation count with reverse leakage current. Even within a single device that contained multiple 1c screw dislocations, the micoplasma turn-on voltages of various 1c screw dislocations was sometimes noticeably different. However, this did not change the general reverse I-V characteristics outside the range of I-V data displayed in Figure 7. Devices with more elementary screw dislocations tended to exhibit higher currents at biases well above microplasma turn-on yet below the bulk breakdown voltage $(75<\mathrm{V}<90 \mathrm{~V}$ in Figure 7). An example of this trend is illustrated in Figure 8, which compares the characteristics of two separate diodes with identical microplasma turn-on voltages. At sufficiently high reverse bias, the diode containing two elementary screw dislocations (which both turned on at $68 \mathrm{~V}$ ) exhibited nearly a factor of two larger current than the diode that contained a single elementary screw dislocation (which also turned on at $68 \mathrm{~V}$ ).

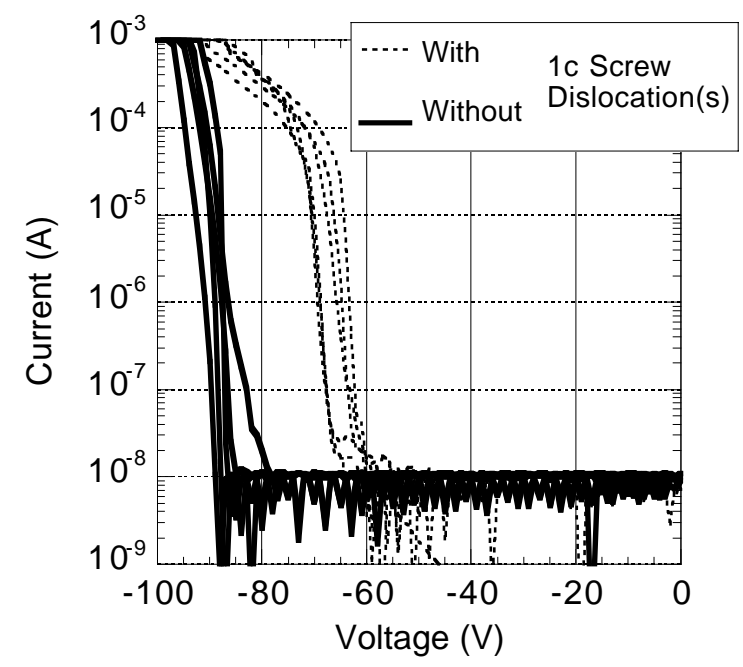

Figure 7: Reverse I-V data comparing 11 diodes with and without 1c screw dislocations that resided in very close proximity to each other (within $1 \mathrm{~mm}$ ) on the wafer.

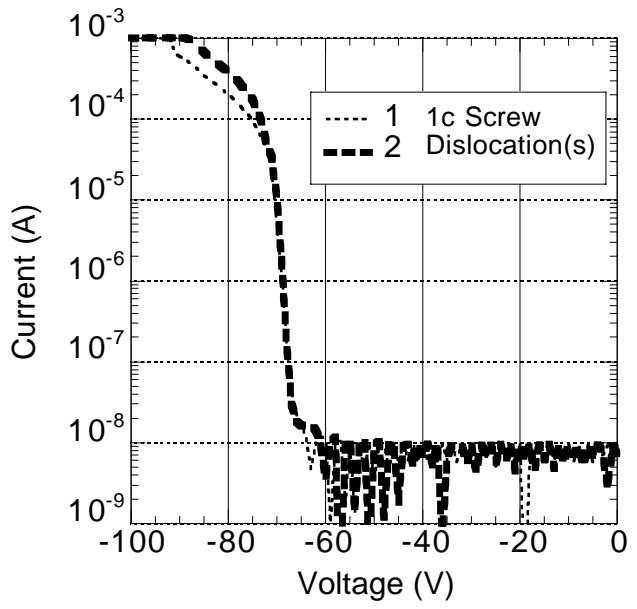

Figure 8: Reverse I-V data comparing two devices, one with 1 1c screw dislocation and the other with 2 1c screw dislocations, where the microplasma turn-on voltage of all three 1c screw dislocations was $68 \mathrm{~V}$. 


\section{DISCUSSION}

The above results clearly indicate that a highly localized junction breakdown is occurring at all elementary screw dislocations within these $4 \mathrm{H}-\mathrm{SiC} \mathrm{p}^{+} \mathrm{n}$ diodes. This data is entirely consistent with the electrical data of Konstantinov et. al. [20,21] who reported similar observations of $4 \mathrm{H}-\mathrm{SiC}$ microplasmas and softened breakdown I-V knees. In contrast to the present study however, Konstantinov et. al. did not attribute the degraded reverse diode characteristics with elementary screw dislocation defects, largely due to the imprecise mapping of defects employed in Reference [20]. Instead of using SWBXT which differentiates various types of crystallographic defects, Konstantinov et. al. employed chemical etching to map defects present in their $4 \mathrm{H}-\mathrm{SiC} \mathrm{p}^{+} \mathrm{n}$ junctions. Chemical etching techniques can indiscriminately delineate electrically unimportant defects residing outside the junction depletion region (such as surface processing damage) in addition to electrically important dislocations running through the electrically active junction region $[12,22]$. In our opinion, this is the reason that uniform breakdown luminescence (no microplasmas) was observed in diodes that later exhibited pits following chemical etching. We suggest that etch pits observed in uniform-breakdown diodes (no microplasmas) are due to defects other than screw dislocations, probably residing near the surface outside the electrically active depletion region. The results of our present study strongly indicate that nonuniform microplasmic breakdowns, such as those observed in References [20] and [21], are due to elementary screw dislocations.

While the exact physical mechanics of the localized $4 \mathrm{H}-\mathrm{SiC}$ breakdown process are uncertain at this time, the general observed behavior is not dissimilar to previously observed defect-assisted breakdown in silicon and other semiconductor pn junctions [23-26]. These works speculate on several possible mechanisms for localized breakdown which might be applicable to the 4H-SiC 1c screw dislocation breakdown observed in this work. Lattice deformation around an elementary screw dislocation is likely to somewhat change the semiconductor band structure in the vicinity of the defect. If this leads to a local reduction in the $4 \mathrm{H}-\mathrm{SiC}$ bandgap, carriers would require slightly less energy to impact ionize, and the probability of breakdown due to carrier tunneling would also increase [27]. Without changing the bandgap itself, other local band structure changes may influence high-field carrier transport and scattering so as to effectively reduce the semiconductor critical field in the near-defect region. The presence of dangling bonds down the core of the screw dislocation may also play a key role in the defect-assisted breakdown process. Another speculation is that enhanced impurity incorporation may arise as the 1c screw dislocation propagates during epilayer growth, which would result in higher doping or deep level impurities near the dislocation that would locally reduce breakdown voltage. It is worth noting that work by Si et. al. [9, 10] has previously shown that many 1c screw dislocations do not run exactly parallel to the crystallographic c-axis, but instead can lie at angles up to $15^{\circ}$ from parallel to the c-axis. Differing angles between the 1c screw dislocations and the applied electric field may therefore account for observed differences in microplasma turn-on voltages. A more complete understanding of the elementary screw dislocation breakdown physics will require further studies.

Between the microplasma turn-on voltage and the bulk breakdown voltage $(\sim 65 \mathrm{~V}<\mathrm{V}<\sim 90 \mathrm{~V}$ in Figure 7), essentially all measured current is flowing through a tiny percentage of the overall diode junction area. Based on the size of the observed microplasmas, one can estimate a $5 \mu \mathrm{m}$ radius for the region of current flow surrounding the 1c screw dislocation defect, which corresponds to an effective breakdown area of $7.85 \times 10^{-7} \mathrm{~cm}^{2}$ for each $1 \mathrm{c}$ screw dislocation. Therefore in Diode B, which has a total area of $2.6 \times 10^{-4} \mathrm{~cm}^{2}$, all breakdown current between 65 $\mathrm{V}$ and $90 \mathrm{~V}$ is flowing through $0.3 \%$ of the total pn junction area. At $0.5 \mathrm{~mA}$ of reverse breakdown current at $85 \mathrm{~V}$ reverse bias (Figure 5b), this corresponds to a localized power density in excess of $54 \mathrm{~kW} / \mathrm{cm}^{2}$ around the screw dislocation defect. Once bias is increased beyond the bulk breakdown voltage, it is uncertain how current flow divides between the elementary screw dislocation and the bulk junction area.

Localized breakdowns and high-current filaments at junction hotspots are undesirable in silicon-based solid-state power devices. In operational practice, silicon power devices that uniformly distribute breakdown current over the entire junction area exhibit much greater reliability than silicon devices that manifest localized breakdown behavior. This is because silicon devices that avoid localized junction breakdown exhibit larger Safe Operating Areas (SOA's) and can much 
better withstand repeated fast-switching stresses and transient overvoltage glitches that arise in high-power systems [27-30]. Positive temperature coefficient of breakdown voltage, a standard behavior in silicon power devices, helps insure that current flow is distributed uniformly throughout a device, instead of concentrated at high-current filaments. To date, positive temperature coefficient of breakdown behavior has only been observed in $4 \mathrm{H}-\mathrm{SiC}$ devices small enough to be free from elementary screw dislocations [31]. Before SiC can become feasible for widespread incorporation into high-power systems, $\mathrm{SiC}$ power devices must demonstrate at least equal, if not superior, reliability characteristics as present-day silicon power devices. Therefore, SiC power devices must demonstrate at least equal, if not superior, SOA's and immunity to switching and overvoltage stresses as silicon power devices.

While the defect-assisted localized breakdown observed for $4 \mathrm{H}-\mathrm{SiC}$ in this work is generally undesirable, its quantitative impact on the viability and reliability of $\mathrm{SiC}$ high-power electronics remains to be assessed. Because of large superiorities in key material properties such as Debye temperature and thermal conductivity [1], it is conceivable that $4 \mathrm{H}-\mathrm{SiC}$ power devices with $1 \mathrm{c}$ screw dislocations might nevertheless exhibit comparable or superior reliability characteristics as defect-free silicon power devices [29, 30]. Given the present absence of experimental $4 \mathrm{H}-\mathrm{SiC}$ device breakdown and switching reliability data (such as mean energy to junction failure testing), extensive future studies are necessary before quantitative conclusions regarding $4 \mathrm{H}-\mathrm{SiC}$ power device reliability can be reached. It is very important that the operational effects of elementary screw dislocations be definitively ascertained, as these defects will be present in all appreciable current $(>1 \mathrm{~A}) 4 \mathrm{H}-\mathrm{SiC}$ power devices manufactured on commercial c-axis wafers for the foreseeable future. Therefore, breakdown and switching reliability studies should immediately be undertaken using a variety of existing prototype $4 \mathrm{H}-\mathrm{SiC}$ devices, both with and without elementary screw dislocations. The resulting data could then be compared with high reliability silicon devices, enabling meaningful extrapolation of the operational reliability of future $4 \mathrm{H}-\mathrm{SiC}$ power devices with and without elementary screw dislocations relative to present-day silicon high-power devices.

\section{CONCLUSIONS}

While not nearly as detrimental to $\mathrm{SiC}$ device performance as micropipes, this paper has demonstrated that elementary screw dislocations somewhat degrade the reverse leakage and breakdown properties of $4 \mathrm{H}-\mathrm{SiC} \mathrm{p}^{+} \mathrm{n}$ diodes. Diodes containing elementary screw dislocations exhibited a $5 \%$ to $35 \%$ reduction in breakdown voltage, higher pre-breakdown reverse leakage current, softer reverse breakdown I-V knee, and microplasmic breakdown current filaments that were non-catastrophic as measured under high series resistance biasing. The nonuniform defectassisted breakdown observed in this work may or may not affect the operational ratings and reliability of high-power $\mathrm{SiC}$ devices. It is important that further studies be undertaken to better quantify the impact of 1c screw dislocations on the breakdown and switching reliability characteristics of various $\mathrm{SiC}$ power device structures.

\section{ACKNOWLEDGMENTS}

The authors would like to gratefully acknowledge the assistance of C. Fazi of U.S. Army Research Laboratory, and D.J. Larkin, J. A. Powell, C. Salupo, G. Beheim, L. Keys, A. Trunek, J. Heisler of NASA Lewis Research Center. Work at NASA Lewis was carried out under joint funding from NASA Lewis Research Center and Defense Advanced Research Projects Agency (DARPA) Order \#D149. X-ray topography research supported in part by the U.S. Army Research Office under contract numbers DAAH04-94-G-0091 and DAAH04-94-G-0121 (contract monitor, Dr. John T. Prater). Topography was carried out at the Stony Brook Synchrotron Topography Facility, beamline X-19C, at the National Synchrotron Light Source, at Brookhaven National Laboratory, which is supported by the U.S. Department of Energy, under contract No. DE-AC02$76 \mathrm{CH} 00016$. 


\section{REFERENCES}

1. P. G. Neudeck, J. Electron. Mater. 24 (4), 283-288 (1995).

2. M. Bhatnagar and B. J. Baliga, IEEE Trans. Electron Devices 40 (3), 645-655 (1993).

3. B. J. Baliga, IEEE Spectrum 32 (7), 34-49 (1995).

4. G. W. Eldridge, D. L. Barrett, A. A. Burk, H. M. Hobgood, R. R. Siergiej, C. D. Brandt, M. A. Tischler, G. L. Bilbro, R. J. Trew, W. H. Clark, and R. W. Gedridge, Jr., American Institute of Aeronautics and Astronautics, Washington, DC, Report No. 93-2703, 1993.

5. W. J. Schaffer, G. H. Negley, K. G. Irvine, and J. W. Palmour in Diamond, SiC, and Nitride Wide-Bandgap Semiconductors, edited by C. H. Carter, Jr., G. Gildenblatt, S. Nakamura, and R. J. Nemanich (Mater. Res. Soc. Proc. 339, Pittsburgh, PA, 1994), pp. 595-600.

6. P. G. Neudeck and J. A. Powell, IEEE Electron Device Lett. 15 (2), 63-65 (1994).

7. S. Wang, M. Dudley, C. H. Carter, Jr., V. F. Tsvetkov, and C. Fazi in Applications of Synchrotron Radiation Techniques to Materials Science, edited by L. Terminello, N. Shinn, G. Ice, K. D'Amico, and D. Perry (Mater. Res. Soc. Proc. 375, Pittsburgh, PA, 1995), pp. 281-286.

8. M. Dudley, S. Wang, W. Huang, C. H. Carter, Jr., and C. Fazi, J. Phys. D 28, A63-A68 (1995).

9. W. Si, M. Dudley, R. Glass, V. Tsvetkov, and C. H. Carter, Jr., J. Electron. Mater. 26 (3), 128-133 (1997).

10. W. Si and M. Dudley, to appear in Silicon Carbide, III-Nitrides, and Related Materials 1997, edited by G. Pensl and H. Morkoc (Trans Tech Publications, Switzerland, 1998).

11. S. Wang, M. Dudley, C. H. Carter, Jr., and H. S. Kong in Diamond, SiC and Nitride Wide Bandgap Semiconductors, edited by C. H. Carter, Jr., G. Gildenblat, S. Nakamura, and R. J. Nemanich (Mater. Res. Soc. Proc. 339, Pittsburgh, PA, 1994), pp. 735-740.

12. J. A. Powell, D. J. Larkin, P. G. Neudeck, J. W. Yang, and P. Pirouz in Silicon Carbide and Related Materials, edited by M. G. Spencer, R. P. Devaty, J. A. Edmond, M. A. Kahn, R. Kaplan, and M. Rahman (Institute of Physics Conference Series no. 137, Bristol, UK, 1994), pp. 161-164.

13. V. F. Tsvetkov, R. C. Glass, D. Henshall, D. A. Asbury, and C. H. Carter, Jr. to appear in Silicon Carbide, III-Nitrides, and Related Materials 1997, edited by G. Pensl and H. Morkoc (Trans Tech Publications, Switzerland, 1998).

14. Cree Research, Inc. Product Data Sheets, 2810 Meridian Parkway, Suite 176, Durham, NC 27713.

15. M. G. Spencer, R. P. Devaty, J. A. Edmond, M. A. Khan, R. Kaplan, and M. Rahman, editors, Silicon Carbide and Related Materials, (Institute of Physics Conference Series no. 137, Bristol, UK, 1994), pp. 465-690.

16. G. Pensl and H. Morkoc, editors,Silicon Carbide, III-Nitrides, and Related Materials 1997, (Trans Tech Publications, Switzerland, 1998). 
17. D. J. Larkin, P. G. Neudeck, J. A. Powell, and L. G. Matus, Appl. Phys. Lett. 65 (13), 1659-1661 (1994).

18. D. J. Larkin, Phys. Status Solidi B 202 (1), 305-320 (1997).

19. M. Dudley, in Encyclopedia of Applied Physics, vol. 21. (Wiley-VCH Verlag GmbH, New York 1997), pp. 533-547.

20. A. O. Konstantinov, N. Nordell, Q. Wahab, and U. Lindefelt, "Ionization Rates and Critical Fields for Uniform Breakdown in 4H SiC," presented at Electronic Materials Conference, Ft. Collins, CO, 1997 (unpublished).

21. A. O. Konstantinov, Q. Wahab, N. Nordell, and U. Lindefelt to appear in Silicon Carbide, III-Nitrides, and Related Materials 1997, edited by G. Pensl and H. Morkoc (Trans Tech Publications, Switzerland, 1998).

22. R. A. Stein and R. Rupp in Silicon Carbide and Related Materials, edited by M. G. Spencer, R. P. Devaty, J. A. Edmond, M. A. Khan, R. Kaplan, and M. Rahman (Institute of Physics Conference Series no. 137, Bristol, UK, 1994), pp. 561-563.

23. A. M. Barnett and A. G. Milnes, J. Appl. Phys. 37 (11), 4215-4223 (1966).

24. A. M. Barnett, in Injection Phenomena, edited by R. K. Willardson and A. C. Beer (Semiconductors and Semimetals 6, Academic Press, New York, 1970), pp. 141-200.

25. A. G. Chynoweth and G. L. Pearson, J. Appl. Phys. 29 (7), 1103-1110 (1958).

26. A. G. Chynoweth, in Physics of III-V Compounds, edited by R. K. Willardson and A. C. Beer (Semiconductors and Semimetals 4, Academic Press, New York, 1968) pp. 307-325.

27. S. M. Sze, Physics of Semiconductor Devices, 2nd. ed., (Wiley-Interscience, New York, 1981).

28. B. J. Baliga, Modern Power Devices, (Wiley-Interscience, New York, 1987).

29. L. W. Ricketts, J. E. Bridges, and J. Miletta, EMP Radiation and Protective Techniques (Wiley-Interscience, New York, 1976).

30. R. N. Ghose, EMP Environment and System Hardness Design (D. White Consultants, Gainesville, VA, 1984).

31. P. Neudeck and C. Fazi, IEEE Electron Device Lett. 18 (3), 96-98 (1997). 